\section{Exploring adolescents' current sources and learning preferences about contraception in a US paediatric emergency department}

In the USA, adolescents who seek care in emergency departments have been shown to be a group at increased risk of pregnancy and sexually transmitted infections because of misuse or non-use of contraception. ${ }^{1}$ Schools are often their traditional source of sexual health education, but school curricula vary greatly, are not always medically accurate, and may focus on abstinence-only education. ${ }^{2}$ In addition, adolescents are less likely to have primary care providers and thus may miss opportunities to receive contraceptive counselling, the emergency department being their only contact with a clinician. ${ }^{1}$ Several studies have shown that adolescent females are interested in being educated about contraception in emergency departments. ${ }^{34}$ We assessed male and female adolescents' current and most trusted sources of contraception education, as well as their interest and preferences for contraception education in the emergency department.

We surveyed a convenience sample of English-speaking adolescents aged 14-21 years presenting to a Level 1, urban paediatric emergency department at a free-standing children's hospital. Patients were excluded if they were critically ill, had a psychiatric chief complaint, or non-English speakers. A multidisciplinary team of authors developed the paper survey tool, which asked questions on demographics, chief complaint, sexual history, current and most trusted sources of contraception education, interest in additional contraception education in the emergency department, and preferred learning methods.

We enrolled 126 out of 143 potential patients $(88 \%)$. The most common reasons for not enrolling were not being interested and not feeling well. The mean age of participants was 16 years; 66 were female and 57 male. Eightyfive were Hispanic.

Thirty-five participants said that they were sexually active, with eight reporting that their last sexual encounter had been unprotected. Ninety-nine participants had a primary care provider, 32 of them reporting that they had learnt about contraception from him or her. Thirteen of the 35 sexually active participants who had a primary care provider had been counselled about contraception by him or her.

The number of respondents presented here does not total 126 as some participants left some of the questions unanswered. Most patients had learnt about contraception at school (109/123); other sources included family $(61 / 123)$, doctor (39/123), friends (35/123) and the internet (24/123), with no significant difference by gender. However, participants' most trusted source was a doctor (63/122), followed by family (59/122), school (21/122), friends 
$(21 / 122)$ and the internet (7/122), again with no significant difference by gender.

Seventy out of 114 patients reported interest in learning about contraception in the emergency department, but only 43 of them reported having been asked about sexual activity during their visit.

Most patients (91/122) preferred to learn about contraception in person, followed by in a handout (37/122). There were no significant differences in learning preference by gender.

To our knowledge, our study is the first to examine the preferences for sexual health education of both males and females in an emergency department. We found that males and females had similar sources of sexual health education, as well as similar learning preferences.

We were surprised at our participants' preference for learning about contraception in person, given that today's adolescents are becoming increasingly immersed in technology, the internet and social media. Mollen et al found that adolescent females prefer to learn about emergency contraception in an emergency department, as well as in person from a provider. ${ }^{5}$ These findings together emphasise the need for interventions to help both primary care providers and emergency clinicians discuss reproductive health with teenagers.

\section{Tatyana Vayngortin, ${ }^{1}$ Diane Tanaka, ${ }^{2,3}$} Deborah Liu, ${ }^{3,4}$ Tracey Wilkinson $^{5}$

'Department of Emergency Medicine, UCSF Benioff Children's Hospital Oakland, Oakland, California, USA

${ }^{2}$ Division of Adolescent Medicine, Children's Hospital of Los Angeles, Los Angeles, California, USA

${ }^{3}$ Keck USC School of Medicine, Los Angeles, California, USA

${ }^{4}$ Division of Emergency Medicine and Transport, Children's Hospital of Los Angeles, Los Angeles, California, USA

${ }^{5}$ Department of Pediatrics, Children's Health Services Research, Indiana University School of Medicine, Indianapolis, Indiana, USA

Correspondence to Dr Tatyana

Vayngortin, Department of Emergency Medicine, UCSF Benioff Children's Hospital Oakland, Oakland, CA 94609, USA; tanyavayngortin@gmail.com

Acknowledgements The authors would like to thank Eugene Nguyen for providing statistical analysis.

Contributors All persons who meet authorship criteria are listed as authors, and all authors certify that they have participated sufficiently in the work to take public responsibility for the content, including participation in the concept, design, analysis, writing or revision of the manuscript. Furthermore, each author certifies that this material or similar material has not been and will not be submitted to or published in any other publication before its appearance in $B M J$ Sexual \& Reproductive Health.

Funding This study was supported by the Gary F Krieger Advocacy Award at Children's Hospital of Los Angeles.

Competing interests None declared.

Patient consent Not required.

Ethics approval Children's Hospital Los Angeles Institutional Review Board.

Provenance and peer review Not commissioned; internally peer reviewed.

Data sharing statement There are no published data from this study. However, these data were presented at a poster session at the Pediatric Academic Societies Meeting in 2015, and the abstract is available in the abstract archive.

(C) Article author(s) (or their employer(s) unless otherwise stated in the text of the article) 2018. All rights reserved. No commercial use is permitted unless otherwise expressly granted.

\section{Check for updates}

BMJ Sex Reprod Health 2018;44:148-149. doi:10.1136/bmjsrh-2017-200045

\section{REFERENCES}

1 Wilson KM, Klein JD. Adolescents who use the emergency department as their usual source of care. Arch Pediatr Adolesc Med 2000;154:361-5.

2 Mauldon J, Luker K. The effects of contraceptive education on method use at first intercourse. Fam Plann Perspect 1996;28:19-24.

3 Fine LC, Mollen CJ. A pilot study to assess candidacy for emergency contraception and interest in sexual health education in a pediatric emergency department population. Pediatr Emerg Care 2010;26:413-6.

4 Chernick LS, Schnall R, Higgins T, et al. Barriers to and enablers of contraceptive use among adolescent females and their interest in an emergency department based intervention. Contraception 2015;91:217-25.

5 Mollen CJ, Miller MK, Hayes KL, et al. Developing emergency departmentbased education about emergency contraception: adolescent preferences. Acad Emerg Med 2013;20:1164-70. 